\title{
Life negative events and depressive symptoms: the China longitudinal ageing social survey
}

\author{
Zhenjie Wang $^{1 * \dagger}$, Hanmo Yang ${ }^{2 \dagger}$, Pianpian Zheng ${ }^{1}$, Bei Liu', Zhanyuan Guo ${ }^{1}$, Shen Geng ${ }^{1}$ and Shenda Hong ${ }^{3}$
}

\begin{abstract}
Background: Although some studies have reported the association between life negative events and depressive disorders, very limited studies have examined the association between life negative events exposure and depressive symptoms risk among Chinese older adults.

Methods: Data were obtained from the China Longitudinal Ageing Social Survey (CLASS), which was a stratified, multi-stage, probabilistic sampling survey, conducted in 2014. General linear regression and logistic regression were used to examine the association between life negative events exposure and depressive symptoms among Chinese older adults.

Results: Life negative events showed statistical dose-response association with depressive symptoms risk after adjustment for the confounding factors $(P$ trend $<0.001)$. Under consideration of life negative events exposure, participants who lived in rural areas, without a spouse or live alone were vulnerable to depressive symptoms.

Conclusions: Life negative events played a risk role of depressive symptoms among Chinese older adults, especially among those in rural areas, females or without a spouse. Our current study is valuable for the development of special prevention depressive symptoms programs among elderly individuals, especially those who have experienced negative events.
\end{abstract}

Keywords: Older adults, Depressive symptoms, Life negative events exposure, China

\section{Background}

Depressive symptoms (DS), which is characterized by symptoms of sadness, depressed mood, and loss of interest, is one of the most prevalent mental disorders across the world [1]. People with DS are usually associated with low quality of life, prevalence of cancer, chronic diseases, suicide, and mortality [2-5]. DS could place a heavy burden on families, communities and health services in both high-income countries and low- and middle-income countries $[6,7]$.

\footnotetext{
* Correspondence: zhenjie.wang@pku.edu.cn

'Zhenjie Wang and Hanmo Yang contributed equally to this work.

${ }^{1}$ Institute of Population Research, Peking University, No. 5 Yiheyuan Road, Haidian District, Beijing 100871, People's Republic of China

Full list of author information is available at the end of the article
}

The prevalence of DS varies widely across countries, from 1 to $16 \%$ among middle-aged and elderly people in studies conducted in developed countries [8-10]. As China is facing rapid urbanization and many environmental challenges, the prevalence of DS has been increasing rapidly from 3.9 to $17 \%$ among elderly Chinese people in past two decades [11-13].

Several socioeconomic variables were presented to be associated with DS risk [14], although the associations are inconsistent $[10,13]$. A number of studies found inverse or $\mathrm{U}$-shaped associations between age and DS [15-17]. Moreover, low socioeconomic status was found to be associated with severe DS in both men and women, and low education level was found to be related

(c) The Author(s). 2020 Open Access This article is licensed under a Creative Commons Attribution 4.0 International License, which permits use, sharing, adaptation, distribution and reproduction in any medium or format, as long as you give appropriate credit to the original author(s) and the source, provide a link to the Creative Commons licence, and indicate if changes were made. The images or other third party material in this article are included in the article's Creative Commons licence, unless indicated otherwise in a credit line to the material. If material is not included in the article's Creative Commons licence and your intended use is not permitted by statutory regulation or exceeds the permitted use, you will need to obtain permission directly from the copyright holder. To view a copy of this licence, visit http://creativecommons.org/licenses/by/4.0/ The Creative Commons Public Domain Dedication waiver (http://creativecommons.org/publicdomain/zero/1.0/) applies to the data made available in this article, unless otherwise stated in a credit line to the data. 
with high risk of DS [18-20]. However, some studies reported no association between income and DS [21] or between education level and DS [14, 17].

Studies have proved that exposure to life negative events, such as serious illnesses, injuries, deaths of loved ones, marital separations, break-ups of steady relationships, onset of unemployment, major financial crises, and so on, is associated with depressive disorders and anxiety $[22,23]$. However, there is limited epidemiologic evidence linking life negative events exposure with DS risk among Chinese older population. Therefore, we investigated the association of recent negative events exposure, including serious diseases (self or family member), natural disaster/accident, the death of a family member (spouse, children, or relatives), with depressive symptoms risk using data from the Chinese Longitudinal Ageing Social Survey (CLASS).

\section{Methods}

\section{Setting and sample}

This survey used a stratified, multi-stage, probabilistic sampling method to select nationally representative sample. Details of the study design and conduct were described elsewhere [24]. There were 11,511 older adults were surveyed in total. In the present study, the sample comprised 8711 subjects aged 60 years or older who answered the questions on depressive symptoms and other independent variables of interests, such as demographic variables, health, health serveries, socioeconomic variables, social support and so on. All the participants were interviewed face-to-face by trained interviewers. During the interview, interviewers should choose an independent and quiet environment, avoid the presence of irrelevant people.

\section{Measurement}

Depressive symptoms were assessed by using a nineitem Center for Epidemiological Studies Depression Scale (CES-D), including three items assessed positive feelings, two items assessed negative emotions, two items assessed somatic symptoms, and two items assessed sense of marginalization. 9-item CES-D was reliable and valid for detecting non-psychotic mental disorders among Chinese older adults [25]. Each item had a score of 0 (rarely or none of the time), 1 (some of the time), or 2 (most of the time), with the total score ranging from 0 to 18 . By reversing the coding of the positive effect items, a higher score indicates a higher level of depressive symptoms. For the current study, on a 9-item scale, the total possible score is 18 ( 9 items multiplied by 2 , the highest response). That total score is divided by 60 (the total possible score on the full 20-item CES-D), which equals 0.3 [26]. Then, the 0.3 is multiplied by 16 , resulting in a standardized cut score of 4.8 for the 9- item form of the CES-D. In this study, the internal Cronbach's alpha for the nine items was 0.75 .

In the current study, the life negative events exposure was the experience of a life negative event reported by the subjects themselves in the past 12 months. The information of the seven life negative events, including serious diseases (self or family member), natural disaster/accident, the death of a family member (spouse, children, or relatives), were collected during the survey. Number of life negative events in past 12 months were counted and further categorized ( 0 " $=0, " 1 "=1$, " $\geq 2$ " = 2). Socio-demographic characteristics included gender (male, female), age, marital status (married, widowed/divorced/unmarried), ethnicity (Han, others), residence (rural, urban), education level (junior high school and above, primary school, never attended school), and living arrangements (lives alone, lives with others). Ten-item version of the activities of daily living (ADL) was assessed for physical disability [27]. Chronic diseases, including any health problems: hypertension, diabetes, heart disease, renal disease, liver disease, stroke, tuberculosis, arthritis, respiratory and so on, were categorized into "yes" =1, and "no" = 0 .

\section{Statistical analysis}

Mean \pm SD (standard deviation) was used for the description of continuous variables and percentage for categorical data. General linear regression was used to examine the association between depressive symptom score and number of life negative events in the past 12 months. Logistic regression analysis was used to estimate odds ratios (OR) and 95\% confidence intervals (CI) of depression risk for each category with the lowest category as the reference group. Trends of the associations were assessed with ordinal scores assigned to categories of the number of life negative events in the past 12 months. Another analysis was done according to sociodemographical status, gender (male, female), residence (rural, urban) and living arrangements (lives alone, lives with others) to examine associations between the number of negative events in the past 12 months and depression risk under considering confounding variables. Statistical significance was declared with a two-sided $p$ value $<0.05$. Statistical analyses were performed using SAS version 9.4 (SAS Institute Inc., Cary, NC, USA).

\section{Results}

Selected characteristics of subjects with/without depressive symptoms (DS) are summarized in Table 1. The overall average Center for Epidemiological Studies Depression Scale (CES-D) score was 4.56 (Standard Deviation: 3.56). The prevalence of DS was $43 \%$ among Chinese population aged over 60 years. In the current study, male subjects, urban residents, people living with 
Table 1 Characteristics distribution among elder population in China

\begin{tabular}{|c|c|c|c|}
\hline \multirow[t]{2}{*}{ Variables } & \multirow{2}{*}{$\begin{array}{l}\text { Sample } \\
\text { size } \\
(n=8177)\end{array}$} & \multicolumn{2}{|l|}{ Depressive symptoms } \\
\hline & & $\begin{array}{l}\text { with depressive symptoms } \\
(n=3542)\end{array}$ & $\begin{array}{l}\text { without depressive symptoms } \\
(n=4635)\end{array}$ \\
\hline Age (years), mean (sd) & $69.07(7.47)$ & $69.53(7.67)$ & $68.73(7.33)$ \\
\hline \multicolumn{4}{|l|}{ Education level } \\
\hline Junior High school and above & 1670 & $931(26.29 \%)$ & 739 (15.94\%) \\
\hline Primary school & 2948 & 1408 (39.75\%) & $1540(33.23 \%)$ \\
\hline Never attended school & 3559 & 1203 (33.96\%) & $2356(50.83 \%)$ \\
\hline \multicolumn{4}{|l|}{ Gender (\%) } \\
\hline Male & 4378 & $1800(50.82 \%)$ & $2578(55.62 \%)$ \\
\hline Female & 3799 & $1742(49.18 \%)$ & $2057(44.38 \%)$ \\
\hline \multicolumn{4}{|l|}{ Marital status (\%) } \\
\hline Married & 5810 & $2258(63.75 \%)$ & $3552(76.63 \%)$ \\
\hline Widowed/divorced/unmarried & 2367 & $1284(36.25 \%)$ & $1083(23.37 \%)$ \\
\hline \multicolumn{4}{|l|}{ Ethnicity } \\
\hline Han & 7659 & 3291 (92.91\%) & 4368 (94.24\%) \\
\hline Others & 518 & $251(7.09 \%)$ & $267(5.76 \%)$ \\
\hline \multicolumn{4}{|l|}{ Residence } \\
\hline Rural & 2801 & $1487(41.98 \%)$ & $1314(28.35 \%)$ \\
\hline Urban & 5376 & $2055(58.02 \%)$ & $3321(71.65 \%)$ \\
\hline \multicolumn{4}{|l|}{ Living arrangement (\%) } \\
\hline Live with others & 7200 & $2972(83.91 \%)$ & $4228(91.22 \%)$ \\
\hline Live alone & 977 & $570(16.09 \%)$ & $407(8.78 \%)$ \\
\hline \multicolumn{4}{|l|}{ Physical disability } \\
\hline No function problems & 7080 & 2799 (79.02\%) & $4281(92.36 \%)$ \\
\hline One and more functioning limitations & 1097 & $743(20.98 \%)$ & $354(7.64 \%)$ \\
\hline \multicolumn{4}{|l|}{ Chronic diseases (\%) } \\
\hline Yes & 5933 & $2909(82.13 \%)$ & $3024(65.24 \%)$ \\
\hline No & 2244 & $633(17.87 \%)$ & $1611(34.76 \%)$ \\
\hline \multicolumn{4}{|c|}{ Number of life negative events in past 12 months } \\
\hline 0 & 5945 & $2328(65.73 \%)$ & $3617(78.04 \%)$ \\
\hline 1 & 1792 & $925(26.11 \%)$ & $867(18.70 \%)$ \\
\hline$\geq 2$ & 440 & $289(8.16 \%)$ & $151(3.26 \%)$ \\
\hline
\end{tabular}

others, and Han nationality accounted for the majority proportion among Chinese old population.

The associations of the number of negative events with DS risk in Table 2. The number of negative events showed statistical association with depression risk after adjustment for the confounding factors $(P$ trend $<0.001)$. Residual confounding by residence area, gender, and living arrangement might be potential concerns because these are positive risk factors for depression. We further analyzed the association of the number of negative events (Table 3) with depression stratified by selected covariates (i.e., residence area, gender, living arrangement, and physical disability). Increased risk of DS was noted in selected covariates. We found the elders who were living in urban areas decreased 30\% risk of DS compared with those lived in rural areas among the elders without any types of negative event. Among the highest category of number of life negative events in past 12 months, the elders who lived in urban areas was lower risk than those who lived in rural areas. The elders who lived alone increased $56 \%$ risk of DS than those who lived with others among the elders without any types of negative event. Old population without a spouse presented a higher risk of DS than those live with a spouse, and the difference became larger as they experienced more life negative events. 
Table 2 Odds ratio (95\% confidence interval) of depressive symptoms risk according to number of life negative events

\begin{tabular}{llll}
\hline & \multicolumn{2}{l}{ Number of life negative events in past 12 months } & $\geq 2$ \\
\cline { 2 - 4 } & 0 & 1 & $289 / 151$ \\
\hline With DS/ Without DS & $2328 / 3617$ & $925 / 867$ & $6.62(4.16)$ \\
DS score, mean (sd) & $4.19(3.36)$ & $5.27(3.74)$ & $2.57(2.08-3.16)$ \\
OR $(95 \% \mathrm{Cl})^{\text {a }}$ & 1 (reference) & $1.54(1.38-1.71)$ & $2.05(1.65-2.54)$ \\
OR $(95 \% ~ C l)^{b}$ & 1 (reference) & $1.35(1.21-1.52)$ & $<.001$ \\
\hline
\end{tabular}

Abbreviations: DS depressive symptoms, $C l$ confidence interval, $O R$ odds ratio

${ }^{a}$ Adjusted for age, gender, residence area, education level, marital status, ethnicity and living arrangement

${ }^{\mathrm{b}}$ Further adjusted for physical disability and chronic diseases

\section{Discussion}

Overall, the prevalence of depressive symptoms (DS) was $43 \%$ among Chinese old population. The result shows that the risk of depression is related to the number of life negative events experienced among Chinese older population.

In China, a large number of studies concerning DS in older adults have emerged [12, 28]. However, the results of prevalence of DS among older adults varied from $6.4 \%$ [29] to $60.3 \%$ [30], which is due to the inconsistent criteria of the measuring tools used and differences in sample sizes and sociocultural contexts. Our prevalence was similar to an observational study [31]. A previous meta-analysis had estimated the prevalence of depressive symptoms $(23.6 \%)$ in Chinese older adult population [12]. It suggested that the prevalence of DS in Chinese older adults has been increasing significantly [12].

Our finding supports the knowledge that adults exposed to at least one negative event might experience trauma-related mental health conditions [32]. Previous studies suggested that the strength and scale of associations between demographic factors and depression among older adults were different across genders [3335]. Our results also indicate that female gender is positively associated with having depressive symptoms in such that elderly female adults were 1.6 times (2.71/ 1.65) more likely to have depressive symptoms than males who have experienced two or more life negative events in the past 12 years, which was in line with the other findings in developing countries [33, 36-38]. The reasons why females were more affected by depression than males could be attributed to biological or environmental factors [12, 39, 40].

Marital status and living arrangement were regarded as very influential factors for depression among Chinese older adults with the number of negative events experienced under consideration. Widowed, divorced or separated older adults have experienced more stressful life

Table 3 Odds ratio (95\% confidence interval) of depressive symptoms risk according to number of life negative events stratified by selected covariates $^{\mathrm{a}}$

\begin{tabular}{|c|c|c|c|c|c|}
\hline & \multicolumn{3}{|c|}{ Number of life negative events in past 12 months } & \multirow[t]{2}{*}{$P_{\text {trend }}$} & \multirow{2}{*}{$\begin{array}{l}P \\
\text { interaction }\end{array}$} \\
\hline & 0 & 1 & $\geq 2$ & & \\
\hline \multicolumn{6}{|l|}{ Residence area ${ }^{b}$} \\
\hline Rural & 1.00 (reference) & $1.22(1.02-1.46)$ & $1.97(1.46-2.66)$ & $<0.001$ & \multirow[t]{2}{*}{0.33} \\
\hline Urban & $0.70(0.62-0.79)$ & $1.01(0.86-1.19)$ & $1.46(1.06-2.01)$ & $<0.001$ & \\
\hline \multicolumn{6}{|l|}{ Gender $^{c}$} \\
\hline Male & 1.00 (reference) & $1.32(1.14-1.54)$ & $1.65(1.25-2.17)$ & $<0.001$ & \multirow[t]{2}{*}{0.06} \\
\hline Female & $0.96(0.85-1.07)$ & $1.33(1.12-1.57)$ & $2.71(1.91-3.85)$ & $<0.001$ & \\
\hline \multicolumn{6}{|l|}{ Marital status $^{d}$} \\
\hline Married & 1.00 (reference) & $1.42(1.24-1.62)$ & $1.91(1.50-2.44)$ & $<0.001$ & \multirow[t]{2}{*}{0.93} \\
\hline Widowed/divorced/unmarried & $1.46(1.27-1.67)$ & $1.77(1.45-2.17)$ & $3.84(2.42-6.11)$ & $<0.001$ & \\
\hline \multicolumn{6}{|l|}{ Living arrangement ${ }^{e}$} \\
\hline Live with others & 1.00 (reference) & $1.35(1.19-1.52)$ & $2.06(1.64-2.59)$ & $<0.001$ & \multirow[t]{2}{*}{0.96} \\
\hline Live alone & $1.56(1.30-1.88)$ & $2.21(1.64-2.98)$ & $3.01(1.62-5.59)$ & 0.008 & \\
\hline
\end{tabular}

Abbreviations: $\mathrm{Cl}$ confidence interval, $\mathrm{OR}$ odds ratio

a Adjusted for age, gender, residence area, education level, marital status, ethnicity, living arrangement, physical disability and chronic diseases

${ }^{\mathrm{b}}$ Models did not include residence area

c Models did not include gender

${ }^{\mathrm{d}}$ Models did not include marital status

e Models did not include living arrangement 
events and have a relatively higher level of loneliness, which is one of the manifestations of depression [12, 41, 42]. Moreover, family member's support was a significant indicator of DS of older adults [12]. A spouse or other family members can take care of and talk to his or her partner who is experiencing stressful/ negative events as much as he or she can receive emotional and spiritual support from his or her partner, which may reduce depression [12].

The strength of current study is that the CLASS was a population-based survey with a large sample. However, our study also has several limitations, which should be a consideration for further researchers. Firstly, the crosssectional design of the baseline of the CLASS does not provide direct evidence of causality. We will be able to extend the current study to determine causality when longitudinal data are available. Moreover, due to data limitations, only the past 12 months' negative events and types of negative events were collected in this study. We could not assess the frequency, length, or intensity of negative events during lifetime, which should be cautioned in future studies. The CLASS was also lack of information on other mental disorders except for depressive symptoms, which should be cautioned in future studies. Additionally, depressive symptoms were different from diagnosis of depressive disorder, that should be noticed for researchers. Lastly, the CLASS does not provide sufficient information on weight, height, smoking, alcohol drinking, and so on, which were suggested as risk factors of depression.

\section{Conclusions}

In conclusion, in this large population-based study among Chinese older population, we found that $43 \%$ of the elders are experiencing depression. Family-related negative events exposure were associated with depression risk and presented dose-response associations. Moreover, characteristics presented the marginally modified association with depression in the current study. Findings of our study are valuable for the development of prevention programs in identifying elderly individuals, who were exposed to life negative events.

\section{Abbreviations}

CLASS: The China Longitudinal Ageing Social Survey; CES-D: Center for Epidemiological Studies Depression Scale

\section{Acknowledgments}

We would like to thank the Institute of Gerontology and National Survey Research Center at Renmin University of China for providing the CLASS data.

\section{Authors' contributions}

ZW initiated the study, analyzed data and wrote the original article. HY provided advice on analyzing data and writing the article. PZ, SG, BL, ZG and $\mathrm{SH}$ contributed to the analysis and interpretation of data and to critical revision of the manuscript for important intellectual content. All authors approved the final version for publication.

\section{Funding}

This work was supported by the Scientific Research Foundation for the Returned Overseas.

Chinese Scholars, State Education Ministry and UKRI's Global Challenge Research Fund.

(ES/P011055/1). The funders had no role in study design, data collection, and analysis, the

writing of the manuscript, or in the decision to submit this article for publication.

\section{Availability of data and materials}

The datasets generated and/or analysed during the current study are available in the China Longitudinal Aging Social Survey (CLASS) repository, http://class.ruc.edu.cn/index.php?r=index/index\&hl=en.

\section{Ethics approval and consent to participate}

All procedures performed in the study involving human participants were in accordance with the ethical standards of the institutional and/or national research committee and with the 1964 Helsinki declaration and its later amendments or comparable ethical standards. The survey was also conducted within the article 38, 39, and 40 of the Constitution of People's Republic of China and the legal framework governed by Chapter I, Article 9 from the statistics law of the People's Republic of China. Therefore, the study was not reviewed by ethics committee. Verbal informed consent was obtained from all individual participants included in the study. The design of this survey was within the article 38, 39, and 40 of the Constitution of People's Republic of China and the legal framework governed by Chapter I, Article 9 from the statistics law of the People's Republic of China. Verbal informed consent was acceptable and was not reviewed by ethics committee. Moreover, the interviewer also had documented the more details information on the process of obtaining informed consent, which included whether agree to attend this study, the time of agree to attend this study, the reasons of disagree to attend this study, and so on. Details of informed consent was stored by the Institute of Gerontology and National Survey Research Center at Renmin University of China.

\section{Consent for publication}

Not applicable.

\section{Competing interests}

Non-financial competing interests.

\section{Author details}

${ }^{1}$ Institute of Population Research, Peking University, No. 5 Yiheyuan Road, Haidian District, Beijing 100871, People's Republic of China. ${ }^{2}$ National School of Development, Peking University, No. 5 Yiheyuan Road, Haidian District, Beijing 100871, People's Republic of China. ${ }^{3}$ School of Computational Science and Engineering, Georgia Institute of Technology, 756 W Peachtree St NW, Atlanta 30308, Georgia, USA.

Received: 13 October 2019 Accepted: 15 June 2020

Published online: 19 June 2020

\section{References}

1. Whiteford HA, Ferrari AJ, Degenhardt L, Feigin V, Vos T. Global burden of mental, neurological, and substance use disorders: an analysis from the global burden of disease study 2010. PLoS One. 2015;10:e0116820.

2. Dalton SO, Laursen TM, Ross L, Mortensen PB, Johansen C. Risk for hospitalization with depression after a cancer diagnosis: a nationwide, population-basedstudy of cancer patients in Denmark from 1973 to 2003. J Clin Oncol. 2009;27:1440-5.

3. Hsu YT, Liao CC, Chang SN, Yang YW, Tsai CH, Chen TL, et al. Increased risk of depression in patients with Parkinson disease: a Nationwide cohort study. Am J Geriatr Psychiatry. 2015;23:934-40.

4. Ayerbe L, Ayis S, Wolfe CD, Rudd AG. Natural history, predictors and outcomes of depression after stroke: systematic review and meta-analysis. Br J Psychiatry. 2013;202:14-21.

5. Cuijpers P, Vogelzangs N, Twisk J, Kleiboer A, Li J, Penninx BW. Comprehensive meta-analysis of excess mortality in depression in the general community versus patients with specific illnesses. Am J Psychiatry. 2014;171:453-62. 
6. World Health Organization. Depression-a global public health concern. 2012, http://hesp-news.org/2012/10/05/depression-a-globalpublic-healthconcern/ [accessed: 29 Nov 2018].

7. Walker ER, McGee RE, Druss BG. Mortality in mental disorders and global disease burden implications: a systematic review and meta-analysis. JAMA Psychiatry. 2015;72:334-41.

8. Wilhelm K, Mitchell P, Slade T, Brownhill S, Andrews G. Prevalence and correlates of DSM-IV major depression in an Australian national survey. J Affect Disord. 2003;75:155-62.

9. Waraich P, Goldner EM, Somers JM, Hsu L. Prevalence and incidence studies of mood disorders: a systematic review of the literature. Can J Psychiatr. 2004:49:124-38.

10. Djernes JK. Prevalence and predictors of depression in populations of elderly: a review. Acta Psychiatr Scand. 2006;113:372-87.

11. Chen R, Copeland JR, Wei L. A meta-analysis of epidemiological studies in depression of older people in the People's republic of China. Int J Geriatr Psychiatry. 1999;14:821-30.

12. Li D, Zhang DJ, Shao JJ, Qi XD, Tian L. A meta-analysis of the prevalence of depressive symptoms in Chinese older adults. Arch Gerontol Geriatr. 2014;58:1-9.

13. Zhang $L, X U Y, N i e ~ H, Z$ hang $Y$, Wu Y. The prevalence of depressive symptoms among the older in China: a meta-analysis. Int J Geriatr Psychiatry. 2012;27:900-6.

14. Gao S, Jin Y, Unverzagt FW, Liang C, Hall KS, Ma F, et al. Correlates of depressive symptoms in rural elderly Chinese. Int I Geriatr Psychiatry. 2009;24:1358-66.

15. Kessler RC, Birnbaum HG, Shahly V, Bromet E, Hwang I, McLaughlin KA, et al. Age differences in the prevalence and co-morbidity of DSM-IV major depressive episodes: results from the WHO world mental health survey initiative. Depress Anxiety. 2010;27:351-64.

16. Pan A, Franco OH, Wang YF, Yu ZJ, Ye XW, Lin X. Prevalence and geographic disparity of depressive symptoms among middle-aged and elderly in China. J Affect Disord. 2008;105:167-75.

17. Yunming L, Changsheng C, Haibo T, Wenjun C, Shanhong F, Yan M, et al. Prevalence and risk factors for depression in older people in Xi'an China: a community-based study. Int J Geriatr Psychiatry. 2012;27:31-9.

18. Lorant V, Croux C, Weich S, Deliège D, Mackenbach J, Ansseau M. Depression and socio-economic risk factors: 7-year longitudinal population study. Br J Psychiatry. 2007;190:293-8.

19. Van de Velde $\mathrm{S}$, Bracke P, Levecque K. Gender differences in depression in 23 European countries. Cross-national variation in the gender gap in depression. Soc Sci Med. 2010;71:305-13.

20. Zhou $X, B i B$, Zheng $L, L i Z$, Yang $H$, Song $H$, et al. The prevalence and risk factors for depression symptoms in a rural Chinese sample population. PLoS One. 2014:9:e99692.

21. van der Wurff FB, Beekman AT, Dijkshoorn H, Spijker JA, Smits CH, Stek ML, et al. Prevalence and risk-factors for depression in elderly Turkish and Moroccan migrants in the Netherlands. J Affect Disord. 2004;83:33-41.

22. Beals J, Belcourt-Dittloff A, Garroutte EM, Croy C, Jervis LL, Whitesell NR, Manson SM, et al. Trauma and conditional risk of posttraumatic stress disorder in two American Indian reservation communities. Soc Psychiatry Psychiatr Epidemiol. 2013;48(6):895-905.

23. Roh S, Brown-Rice KA, Lee KH, Lee Y-S, Lawler MJ, Martin Jl. Stressors, coping resources, and depressive symptoms among rural American Indian older adults. Social Work in Public Health. 2015a;30(4):345-59.

24. Guo Q, Bai X, Feng N. Social participation and depressive symptoms among Chinese older adults: a study on rural-urban differences. J Affect Disord. 2018;239:124-30

25. Merril S, Zhen C, Shuzhuo L. Intergenerational transfers and living arrangements of older people in rural China: consequences for psychological wellbeing. J Gerontol. 2006;61:S256-66.

26. Kohout FJ, Berkman LF, Evans DA, Cornoni-Huntley J. Two shorter forms of the CES-D depression symptoms index. J Aging Health. 1993;5(2):179-93.

27. Feng Q, Zhen Z, Gu D, Wu B, Duncan PW, Purser JL. Trends in ADL and IADL disability in community-dwelling older adults in Shanghai, China, 1998-2008. J. Gerontol. 2013:68:476-85.

28. Zhang $L, X u Y$, Nie HW. Prevalence of depression among Chinese elderly people in 2000-2010: a mate analysis. Chin J Gerontol. 2011;31(17):3349-52.

29. Chen J, Zhang LM, Gao L. Depressive symptom and its influence factor in urban old adults in Wuhan. Chin J Gerontol. 2007;27(3):275-6.

30. Jia LN, Zhuang HL, Wang XY, Liu FF, Chen BY, Lin YJ. Depression status of the elderly and its relationship with quality of life in community of Fuzhou city. Chin J Geriatrics. 2011;30(11):970-3.
31. Yu J, Li J, Cuijpers P, Wu S, Wu Z. Prevalence and correlates of depressive symptoms in Chinese older adults: a population-based study. Int I Geriatric Psychiatry. 2012;27(3):305-12.

32. Bonanno GA. Resilience in the face of loss and potential trauma. Curr Dir Psychol Sci. 2005;14(3):135-8.

33. Assil S, Zeidan Z. Prevalence of depression and associated factors among elderly Sudanese: a household survey in Khartoum State/Prévalence de la dépression et des acteurs associés chez des Soudanais âgés: enquête auprès des ménages dans l'État de Khartoum. East Mediterr Health J. 2013; 19(5):435.

34. Chui P, Chan M. Prevalence of depressive symptoms and associated factors in patients attending a geriatric day hospital. Asian J Gerontol Geriatr. 2006; $1(2): 73-7$.

35. Goud AA, Nikhade NS. Prevalence of depression in older adults living in old age home. Int Archives Integrated Med. 2015;2(11):1-5.40.

36. Najim H, Omer AA. Sociodemographic and clinical features of patients with depressive disorder in Khartoum. Sudan Psychiatr Danub. 2015;27(1):S240-2.

37. Cole MG, Dendukuri N. Risk factors for depression among elderly community subjects: a systematic review and meta-analysis. Am J Psychiatry. 2003;160(6):1147-56.

38. Bartels M, Cacioppo JT, van Beijsterveldt TC, Boomsma DI. Exploring the association between well-being and psychopathology in adolescents. Behav Genet. 2013;43:177-90

39. McEwen BS, Milner TA. Understanding the broad influence of sex hormones and sex differences in the brain. J Neurosci Res. 2017;95:24-39.

40. Chen Y, Hicks A, While AE. Depression and related factors in older people in China: a systematic review. Rev Clin Gerontol. 2012;1 (1):1-16.

41. Chong MY, Tsang HY, Chen CS, Tang TC, Chen CC, Yeh TL, et al. Community study of depression in old age in Taiwan: prevalence, life events and socio-demographic correlates. Br J Psychiatry. 2001;178(1):29-35.

42. Rashid A, Manan A, Rohana S. Depression among the elderly Malays living in rural Malaysia. Internet J Public Health. 2011;1(2):128-36.

\section{Publisher's Note}

Springer Nature remains neutral with regard to jurisdictional claims in published maps and institutional affiliations.

Ready to submit your research? Choose BMC and benefit from:

- fast, convenient online submission

- thorough peer review by experienced researchers in your field

- rapid publication on acceptance

- support for research data, including large and complex data types

- gold Open Access which fosters wider collaboration and increased citations

- maximum visibility for your research: over $100 \mathrm{M}$ website views per year

At $\mathrm{BMC}$, research is always in progress.

Learn more biomedcentral.com/submissions 